\title{
The Attitudes of Males towards Male- Circumcision in Matobo District of Zimbabwe with Special Reference to Gulathi Area in Matabeleland South Province.
}

\author{
${ }^{1}$ Nkala Printah Printer, ${ }^{2}$ Mbuisa, B.
}

\begin{abstract}
This study sought to assess the attitudes of males towards male circumcision in Matobo district with special attention to Gulathi area. Male circumcision is one of the popular intervention methods that is fully supported by modern health medical practitioners to circumvent the transmission of HIV infection (UNAIDS, 2007). The District AIDS Action Committee (2014) reported that, of the total males circumcised in 2013, about $63 \%$ were below 15 years, therefore, the concern of this study was to investigate the attitudes of males above 15 years towards the circumcision programme. A descriptive survey design was employed for the study while a questionnaire and semi-structured interview were triangulated to elicit data. The target population for the study was of males between the 15-49 years age group. Data were presented in tables and bar charts and analyzed using frequent counts, percentages, Likert Scale and descriptive summaries. The major finding revealed that most men have anxiety of participating in male circumcision programme in which they are expected to first undergo HIV screening before the procedure. In addition, the majority of the respondents do not view circumcision as part of their cultural practices and had negative perceptions based on the belief that circumcision reduces libido or sexual pleasure. The study concluded that low levels of participation in male circumcision programme had cultural and traditional implications. The study recommended that there is need for more educational programmes in schools as well as in the community, fundamentally designed to conscientize the expected programme beneficiaries about the goals and expected achievements. There is also need to involve community members in the programme implementation rather involving only health personnel from divergent cultural backgrounds that contradicts local traditional values and practices. Lastly, advocating for a policy which provides free will of going through circumcision without going through HIV screening needs to be considered.
\end{abstract}

Keywords: Circumcision; Attitudes;

\section{Background to the Study}

The general purpose of male circumcision is to minimize the transmission of HIV pandemic which has resulted in unprecedented suffering among today's families (UNAIDS, 2007). As a result of new HIV infection reported in the world today, this gives to a need to identify new interventions of minimizing its spread. WHO and UNAIDS (2007) states that there is a need for methods to add to the existing ones and male circumcision being identified as one of these new potential methods. The existing ones, according to Guidelines for Antiretroviral Therapy in Zimbabwe (2010) include; public health education, promotion of testing and counselling for HIV and AIDS and prevention of mother-to-child transmission of HIV. Circumcision was discovered to be a preventive method to many sexual problems like; philmosis, paraphimosis posthitis, balanitis and also reduces risks of a number of diseases, caused by the genital tract, (Hargreave, 2007). During the $19^{\text {th }}$ century it was assumed that diseases like epilepsy, rheumatism, cancer and many others were linked to masturbation. Traditional healers in some parts of African communities encouraged circumcision to prevent sexually transmitted infections. Others believe that circumcision arose as a mark of defilement or slavery.

Male circumcision has been practiced by many different cultural groups for many thousands of years. Male circumcision is one of the oldest and most common surgical procedures worldwide which was undertaken for many reasons; religious, cultural, social and medical purposes. According to Dunsmuir and Gordon, (1999), male circumcision is a procedure in which some or the entire foreskin of the penis is removed with a sharp blade. Most anthropologists believe that the practice originated from Egypt and spread to the rest of the world. Hagazy ans Al-Rukba (2012) suggested that the procedure originated in Egypt over 15000 years ago and spread throughout heliolithic cultures across the world during pre-historic migration in ancient times. Linking with the above, Dunsmuir and Gordon (1999) noted that, the earliest Egyptian mummies 1300BC were circumcised and wall paintings in Egypt show it was customarily done about several thousand years earlier than that, suggestive of being in the practice for many years. Others believe that circumcision arose as a mark of defilement or slavery (Dunsmuir and Gordo, 1999: De Vaus, 2001: Warren, 2012). Circumcision was a way of reducing and deliberately instituted to dehumanize a man showing his conquerors were in total control of his manhood. 
Within that context, foreskins of the captives were regarded as the highest trophy a warrior would bring as the symbol of victory to the king. Gayre and Gayre (1972) add that in 1 Samuel 18 verse 25 'The king desires no other bride price except one hundred Philistine foreskins...' Circumcision was just as degrading and evolved as a sufficiently humiliating and deplorable excise in the ancient times; eventually all male descendants of the slaves were subjected and ridiculed to circumcision as symbol to differentiate the 'master' from the captive. Warren (2012) noted that the earliest biblical reference to circumcision appears in the book of Exodus 4 verses 24-26 showing that Moses' infant son was circumcised by its mother using a flint knife. The use of the knife suggests that the practice of circumcision occurred during the Stone Age, many thousands of years ago. The bible further adds that a covenant was made between Abraham and God in which Abraham would be ordained father of a multitude of nations and circumcision was proffered to him and all his male descendents on the eighth day of their birth (WHO \& UNAIDS, 2007: Warren, 2012). The Jews and the Moslems as the descendents of Abraham have been practicing circumcision as a sacred rite. Christians hold conflicting views about the male circumcision, for example, the Roman Catholic in 1442 saw male circumcision as unnecessary ritual act, while Christian churches in South Africa viewed it as a pan ritual while others including the Nomiya in Kenya require circumcision for membership (UNAIDS 2007).

In Africa, circumcision was carried out mostly for religious or cultural purposes. For example, there are countries with more than $80 \%$ rate of circumcision and some are Benin, Cameroon, Gabon, Democratic Republic of Congo, Ghana, Guinea, Kenya, Liberia, Nigeria, and Sierra Leon. On the other hand, there are also countries with less than 20\% circumcision such as Botswana, Malawi, Mozambique, Namibia, Swaziland Zambia, and Zimbabawe (UNAIDS and WHO, 2009). This indicates that Zimbabwe is not a really traditional circumcising country though a few tribal groups found in the country such as the Xhosa and the Shangani whose origins are in South Africa and the Tonga believed to be the descendents of the early inhabitants of the north eastern part of Zimbabwe. To link with the above, Mandva, Mutonhori and Mudzane (2012) state that the Shangani people of Chiredzi constitute the biggest fraction of people who practice circumcision in Zimbabwe, and they actually claim in their language, 'Hoko, tumbuluko waXichangana' (Circumcision is a Shangani traditional rite). Circumcision was found to be a preventive method to many sexual problems. Studies carried out in three African countries between 2004 and 2007 proved that male circumcision may reduce chances of HIV acquisition (Hargreave 2010). Researchers have been exploring the possibility of correlation between Male Circumcision and lowered risk of HIV infection almost since the beginning of the HIV/AIDS epidemic. Results from a randomized controlled trial in South Africa in 2005, indicate that MC protects men against the acquisition of HIV through heterosexual intercourse. On the same vein, Zimbabwe National HIV/AIDS Strategic Plan (2011) acknowledged that medical science shows that male circumcision can reduce the probability of HIV infection in an HIV negative male by $60 \%$. The protection against HIV is the main reason why many boys seek circumcision. It is established that for a male to undergo or not, depends on two factors; communities which traditionally practice circumcision, the rate of participation in those communities is very high, and knowledge that circumcision protects people from acquiring HIV is another strong motivator (WHO and UNAIDS, 2007). According to Gwata (2009), a number of interviewees pointed out that those with brothers and fathers who were circumcised felt compelled to participate in ritual. In support of finding, Meintjes (2010), the desire to legitimatize the practice of circumcision is depended upon the extent to which the majority of the boys are circumcised in the community. For example, the Shangani boys proudly proclaim 'Hiya hkweni' that is, 'we are going to become men', (Mandova, Mutohori and Mudzamire, 2012). The Shangani and the Xhosa do not need to be pushed to be circumcised, for them it has been part of the traditional practice. The protection against HIV is another important motive for boys and men to opt for circumcision. Macintyre, Moses, Pous, Bornstan, Ochieng, Muraguri, Peacock, Cherutich, Hurley and Bertrand (2007), their study revealed that, partial protection against HIV, improved hygiene, increased sexual satisfaction and social acceptance were reported as the major factors that influenced men to participate in circumcision practice. WHO and UNAIDS (2007) state that circumcision was widely perceived to protect against infections and allow easier identification of sores and ulcers permitting easier treatment. This is directed to those with genital sores which might be painless, for example, syphilis sores.

Another school of thought believes that circumcision enhances sexual pleasure. According to Hargreave (2010), there have been concerns that both male and female sexual enjoyment is compromised by male circumcision, a consistent findings to prolongation of ejaculation, latency time, which may be an added advantage in young men where quick ejaculation is very frequent. In countries like Thailand, Nigeria and Kenya, Bonner (2001) in Nkosi (2013) states that, male circumcision is said to enhance pleasure. However, Noel (2006) concluded overall satisfaction rates despite slightly reduced erectile function and decreased penile sensitivity. Depending on the cultural values and norms of a particular community, men and boys undergo circumcision for fear of being stigmatized especially if the majority is circumcised. For example, no matter how grown up they may be, but if they did not participate in circumcision ritual practice, they remain treated as immature individuals who are not expected to make adult decisions such as being involved in marriage issues. 
Male circumcision is thus revered and venerated in some cultures by being considered as a rite of passage marking a boy's entrance into adulthood.

\section{Factors that hinder men's participation in circumcision}

Issues such as program implementation, physical pain resulting from the cutting off of the fore skin of the penis, the required abstinence period following the surgery and related complications including chances of human error, cultural and traditional values and belief systems that define what is accepted and unaccepted influence men's participation in the circumcision. Circumcision as a health medical program whose fundamental aim is to ameliorate human life should involve community members in its implementation phases. According to Meredith \& Mantel, (2010), the importance of locals in program implementation cannot be overemphasized. For example, project implementers are ill-advised to fully introduce a project without adequate preparation in the culture and language of the host community (Chihambakwe \& Nkala, 2012). It is therefore important that health practitioners who are employed to implement the programme should be fluent in the community's language to demystify the beliefs that circumcision should only be carried out in cultural groups that have a historically supportive traditional background. The same authors suggest that if the service providers are not fully accepted by the locals, the program is likely to fail to achieve its intended goals. This study intended to reveal whether programme implementers include locals, if not to assess whether such argument has an impact in the social health environment of Gulathi District of Matabeleland South.

In addition to the noted factors that hinder males' participation in circumcision programme, Gwata (2009) observed that males might hesitate to go for circumcision in fear of being asked to be screened for HIV before being circumcised. Before carryout this study, the researcher observed that those who want to be circumcised are compelled to be firstly tested for their HIV status before undertaking male circumcision as promulgated in the health medical policy of male circumcision. Such a scenario is likely to scare males to participate in the service delivery. From a psychological perspective most males are socialized to restrain seeking medical assistance except on severe serious health concerns as well as delay seeking urgent psychological counselling services (Nelson-Jones2001). It is also essential to note that in some nonecircumcising communities, stigmatization is associated with circumcision (WHO \& UNAIDS (2009). In noncircumcising communities men are branded as perpetrators of HIV infection. In addition, it is wrong to view circumcision as a complete protection, when in fact protection is far less than approximated 50\% (UNAIDS 2009). There are also concerns regarding safety and pain. Many non- circumcising ethnical groups cite endurance of pain as a key component in the rite to passage. Circumcision is widely understood as a surgical procedure with inherent risks. Cases of clients bleeding to death due to improper informal methods are common, which may negatively affect the rate of participation in programme (Sawires, Dowrkin \& Coates, 2007).

Matabeleland South Province is a predominantly non-circumcising community which is assumed may influence men's attitudes towards the programme. This study therefore is concerned with how the programme has gained momentum in helping the community protect itself from the spread of HIV infection. It is of grandeur significance to note that Zimbabwe like its neighbouring countries man circumcision is no longer just a cultural or religious obligation but a powerful tool used by health institutions to contribute towards the reduction and prevention of HIV infection. Ever since African health systems adopted safe male circumcision, many studies are necessary to investigate to identify the strengths and weaknesses of programme implementation and come up recommendations that are designed to ameliorate the needs of its citizens. The importance of this study cannot be overstated because it is hoped it will add value to the scientific knowledge.

\section{Brief Profile of Gulathi Area}

Gulathi area lies in Matobo district in Matabeleland South Province. Matobo district is divided into Matobo South and Matobo North, of which Gulathi is situated in Matobo North region. Historically, the Lozwi people are believed to be the first inhabitants of Gulathi area, but currently, the main ethnic groups are the Ndebeles and the Kalangas. Gulathi area has seven villages, a few farms nearby and some pockets of mines. Four schools and one rural health centre are found in the area with two business centers which service Gulathi area. The majority of the inhabitants come from non-circumcising ancestries, as such circumcision was not pronounced until recently when it was brought as a HIV/AIDS preventive measure. Most of the Gulathi inhabitants have average educational background and either believe in Christianity or in African Traditional Religion.

\section{Statement of the Problem}

Matabeleland South Province is predominantly comprised of non-circumcising community which is assumed influences men's attitudes towards whether to participate or not to be involved in the exercise. It is noticed that in some communities, circumcision is carried out mostly for cultural or religious purposes; consequently, there are high levels of participation. However, in the current situation, male circumcision is a 
protective health programme against HIV infection. Male Circumcision presents challenges especially among non-circumcising groups. For example, there are concerns regarding safety, pain and stigmatization by branding men as perpetrators of HIV infection, and other people are likely to view male circumcision as surgical procedure with inherent risks. This study, therefore, is concerned with the low numbers of men who come for circumcision which is assumed is driven by their attitudes. With fewer numbers of men taking part in circumcision programme, it is a major cause for concern, which this study intended to reveal.

\section{Purpose of the study}

The purpose of this study is to;

- Investigate the attitudes of males towards male circumcision programme at Matobo district with special reference to Gulathi Area.

- Explore ways of conscientizing males to have positive attitudes towards male circumcision.

\section{Research Questions \\ Main/Central Research Question}

- What are the attitudes males at Gulathi area towards male circumcision?

\section{Sub-problems}

- Are men adequately conscientized to comprehend the benefits of man circumcision?

- How do men's attitudes influence their behaviours towards circumcision?

- What factors hinder men to participate in the men circumcision programme?

- What are the sexual behaviours of men after circumcision?

- What strategies can be introduced to improve the participation of men in the circumcision programme?

\section{Scope of the Study (Delimitation)}

The study focused on males in Gulathi area particularly the 15 to 49 years age group which was the target population. The selected area represents other areas in the province which are predominately comprised of non-circumcising communities.

\section{Limitations of the Study}

The following factors were posed as the limitations of this study;

- Some interviewees might have found the study to be sensitive and became suspicious of their involvement especially issues that relate to sexuality are not openly discussed in some cultures. The researcher assured the participants that the findings of the study would not reveal their actual names but rather on the overall contents.

- There might have been some respondents who exhibit only socially acceptable views or became defensive when asked questions that trigger sexual problems, to overcome this, the researcher assured them that the data would be treated with confidentiality and that anonymity would be guaranteed through the use of pseudonyms (Creswell, 2007).

\section{Research Methodology}

This part of the study highlights the methodology that was used to assess the attitudes of men towards the circumcision programme. The methodology comprise the principles, procedures and techniques that direct a chosen research study (Borg \& Gall, 1996).In this study the researcher employed a descriptive survey which combines quantitative and qualitative paradigms to triangulate methods to offset the limitations of the other (Creswell \& Plato,2011).

\section{Population}

Population is the entire pool of subjects or participants that have common characteristics that are of interest to the research (Marezyk, DeMatteo \& Festnger, 2005). Zimbabwe Central Statistical (2012), noted that there were 2494 males at Gulathi area of which 54, 6\% were males between the ages of 15 and 49 years which accounted for 1362 males. For the purpose of this study, the target population was males between 15 to 49 years.

\section{Sampling Technique}

Stratified random sampling technique and convenience sampling techniques were used to come up with a sample of research participants. The population was divided into two main categories (circumcised and noncircumcised males) that were randomly stratified and three health workers who conduct circumcision were chosen through convenience sampling. 


\section{Data Presentation and Analysis}

Data were presented on tables, frequency counts, percentages and descriptive summaries were used in conjunction with Likert Scale to analyze the data.

\section{Findings}

Table 1: Assessment of Males' understanding of the Programme of Male Circumcision. Question: Have you been informed about the benefits of Male Circumcision?

\begin{tabular}{|l|l|l|l|}
\hline AGE RANGE & YES & NO & TOTAL \\
\hline $15----21$ YEARS & 15 & --- & 15 \\
\hline $21---35$ & 35 & --- & 35 \\
\hline $35---42$ & 17 & --- & 17 \\
\hline $42----49$ & 16 & --- & 16 \\
\hline Total & 83 & 0 & 83 \\
\hline & & & \\
\hline & & & \\
\hline
\end{tabular}

The table indicates that all the age groups are conversant about the medical philosophy behind the implementation of Male Circumcision although some lacked in-depth knowledge about context of the phenomenon. The interviewed participants identified the following as the major sources of information: schools, radio, posters found in clinics and television. However, it was noticed that there are households who did not possess radios and televisions which affected their knowledge of the programme.

Table 2: Participants' Knowledge about Male Circumcision.

$\mathrm{N}=83$

\begin{tabular}{|l|l|l|l|l|l|l|}
\hline Question & YES & NO & NO & f & & \multicolumn{2}{l|}{ TOTAL } & f & \\
\cline { 2 - 7 } & $\mathrm{f}$ & & & & & \\
\hline $\begin{array}{l}\text { Do you think MC is an } \\
\text { important Health Medical } \\
\text { Program? }\end{array}$ & 72 & 83 & 13 & 15 & 83 & 100 \\
\hline $\begin{array}{l}\text { Are there any risks } \\
\text { associated with MC? }\end{array}$ & 60 & 73 & 23 & 27 & 83 & 100 \\
\hline & & & & & & \\
\hline
\end{tabular}

The table shows that the majority $(72 \%)$ of the respondents is knowledgeable about the importance of the circumcision programme, however, (13) seemed to lack this basic knowledge, a clear indication that there is need to initiate a vigorous campaign designed to disseminate this crucial information to circumvent distortions and misperceptions. The programme implementers lack resources such as transport to access villages in this mountainous area. Although the majority of the respondents are conversant with the programme, sixty of the respondents displayed their fears about being circumcised. During the interview, some respondents disclosed mythical issues; some believe that circumcision leads to impotence while others did not have confidence in the programme implementers whom they accused for coming from different tribal backgrounds without eloquently communicating in the local languages.

Table 3: Participants' Attitudes towards Male Circumcision

$\mathbf{N}=83$

\begin{tabular}{|c|c|c|c|c|c|c|c|c|c|c|c|c|}
\hline \multirow[t]{2}{*}{ Question } & \multicolumn{2}{|l|}{ SA } & \multicolumn{2}{|l|}{ A } & \multicolumn{2}{|c|}{ NS } & \multicolumn{2}{|l|}{$\mathrm{D}$} & \multicolumn{2}{|c|}{ SD } & \multicolumn{2}{|c|}{ TOTAL } \\
\hline & $\mathrm{f}$ & $\%$ & $\mathrm{f}$ & $\%$ & $\mathrm{f}$ & $\%$ & $\mathrm{f}$ & $\%$ & $\mathrm{f}$ & $\%$ & $\mathrm{f}$ & $\%$ \\
\hline $\begin{array}{l}\text { MC protects people from acquiring HIV and other related } \\
\text { diseases. }\end{array}$ & 41 & 49 & 17 & 20 & 5 & 6 & 9 & 11 & 11 & 13 & 83 & 100 \\
\hline $\begin{array}{l}\text { Does the community encourage males to go for male } \\
\text { circumcision? }\end{array}$ & 20 & 24 & 28 & 34 & 7 & 8 & 16 & 19 & 12 & 14 & 83 & 100 \\
\hline $\begin{array}{l}\text { Does culture influence men's participation in the } \mathrm{MC} \\
\text { Programme? }\end{array}$ & 3 & 4 & 13 & 16 & 6 & 7 & 36 & 43 & 25 & 30 & 83 & 100 \\
\hline Do you think circumcision influences sexual pleasure? & 17 & 20 & 17 & 20 & 8 & 10 & 21 & 25 & 20 & 24 & 83 & 100 \\
\hline $\begin{array}{l}\text { Does your partner influence your decision whether or not to } \\
\text { participate in the circumcision program? }\end{array}$ & 16 & 19 & 20 & 24 & 9 & 11 & 18 & 22 & 20 & 24 & 83 & 100 \\
\hline Does your religion influence males to be circumcised? & 0 & 0 & 5 & 6 & 5 & 6 & 38 & 46 & 32 & 39 & 83 & 100 \\
\hline
\end{tabular}

Forty-one (49\%) and seventeen (20\%) strongly agreed and agreed respectively making a total of fiftyeight $(69 \%)$ view male circumcision as a programme that protects people from acquiring HIV/AIDS pandemic and other related diseases. A total number of forty-eight respondents, ( which is below the number of the total 
participants) confirmed that the community does not significantly motivate its members to undergo male circumcision. Thirty-six (43) disagreed and twenty-five (30\%) strongly disagreed making a total of sixty-one (73\%) that culture does not influence their participation in the programme. This study also revealed that Gulathi area is a patriarchal community in which males dominant in decision-making by indulging into male circumcision programme without firstly consulting with their spouses. Such behaviours are a symptom bearer of dysfunctional relationships in which women have less or little control over their conjugal rights. On the question whether their religious or cultural practices influence males to undertake circumcision, thirty-two (39\%) disagreed and strongly thirty-eight (46\%) making a total of seventy $(85 \%)$ claimed that they are not influenced, which confirms that Gulathi area is a non- circumcising community.

Table 4: Evaluation of Sexual Behaviour of Men after the Circumcision.

\begin{tabular}{|c|c|c|c|c|c|c|}
\hline \multirow[t]{2}{*}{ Question } & \multicolumn{2}{|c|}{ YES } & \multicolumn{2}{|c|}{ NO } & \multicolumn{2}{|c|}{ TOTAL } \\
\hline & f & $\%$ & f & $\%$ & f & $\%$ \\
\hline Did you abstain from sexual intercourse 6 weeks after circumcision? & 35 & 70 & 15 & 30 & 50 & 100 \\
\hline Are you sticking to one partner after the circumcision? & 28 & 56 & 22 & 44 & 50 & 100 \\
\hline Does male circumcision offer full protection against HIV? & 45 & 90 & 5 & 10 & 50 & 100 \\
\hline Has your sexual libido changed as a result of male circumcision status? & 8 & 16 & 42 & 84 & 50 & 100 \\
\hline $\begin{array}{l}\text { Does your spouse show more sexual happiness than before your } \\
\text { circumcision? }\end{array}$ & 40 & 80 & 10 & 20 & 50 & 100 \\
\hline
\end{tabular}

Seventy percent confirmed that they abstained from sexual-intercourse as espoused by the programme implementers. It is noted that only twenty-eight $(56 \%)$ of those who were circumcised revealed that they stuck to one partner while forty- four $(50 \%)$ disclosed that they were involved in multi-sexual encounters. Most of these were not formally married who viewed male circumcision as a fully preventive HIV programme which is of great concern since such information is not true. In this study, forty-two (84\%) of the respondents confirmed that male circumcision did not affect sexual libido. However, they were of the feeling that female partners exhibit increased sexual happiness as a result of removed foreskins.

\section{Focus Group Discussion}

Two focus group discussions were conducted. Each focus group discussion was comprised of participants between the ages of 15 to 49 years which included the unmarried, married, widowers and polygamists. The participants held different positions in the community such as pastors, kraal-heads, traditional healers, Arex Officials, ministry of health workers and the general villagers. The three main themes identified during data analysis were;

- Level of understanding of the benefits of male circumcision,

- Mindset of males towards male circumcision,

- Factors that hinder male circumcision.

\section{Level of understanding of the benefits of male circumcision}

When participants were asked whether they have heard about male circumcision, they all said they had been informed. Participant D. said "he heard about male circumcision when he was still a young boy", three other participants supported him.

When asked for the reasons why circumcision was done, most of the participants said it was done to prevent sexually transmitted infections. Participant A quoted: "It was also done for hygienic purposes, while participant J. disclosed that he was informed by the Xhosa people in Ntabazinduna (an area that is inhabitated by the remnants of the descendents of a South African ethnic group that accompanied the Pioneer Column in the 1870 s), where circumcision is a cultural traditional practice. When asked about their recent sources of male circumcision information, the majority of the participants identified the clinic while about six participants said they were informed through the radio.

When asked whether there were any advantages associated with male circumcision, participant $\mathrm{N}$ who said that he was circumcised when he was a boy asserted "the reason why these young people are dying is because of the foreskin which harbors infection". In both the focus group discussions, all participants agreed that, circumcision is good for hygienic and prevention of some STIs and it was done for cultural reasons. Participants B and M said "it was also done to satisfy a woman sexually". 


\section{Mindset of males towards male circucision}

On the knowledge of traditional beliefs that may negatively influence the uptake of male circumcision, both groups gave similar responses by indicating that there are no such beliefs or they have never heard of them. One participant said "circumcision is an individual decision and cultural decision."

When asked whether it was part of their culture to be circumcised, the majority said that it was not part of their culture. One participant said "we have not yet grasped everything we need to know about this practice." To the researchers, this indicated that people lack in-depth knowledge about the benefits and limitations the male circumcision programme.

On preferred places to undergo male circumcision if the participants' relatives were to opt for the procedure, (because the programme was targeting the 49 years and below only) the majority of the participants in both groups chose the clinic because of the expertise from health medical practitioners, and the availability of anesthetic agents that they were likely to receive which was viewed as contrary to the informal circumcision practice which compromised people's health.

When asked whether male circumcision has any effect on sexual pleasure, mixed feelings were revealed; one participant said, "Circumcision has an effect on sexual pleasure because circumcised men enjoy more pleasure than the uncircumcised ones." The other participant said, "This can only be true if circumcision was done during childhood, and one had no idea about the other world." However, participant Z stated; "A circumcised man is more likely to satisfy a woman than the uncircumcised one because the fore skin impedes the penetration of the penis." This part of discussion indicated that there are a lot of grey areas that need the programme implementers and policy-makers to tackle in the form of educating and conscientizing the society about the nit grit ties of the context of the male circumcision programme.

\section{Factors that hinder male participation in circumcision}

When asked about whether sexual partners have any influence towards men's decision to be circumcised, two participants felt that there was no need for them to consult their spouses before attending to surgical programme. Participant K vehemently argued; "Culturally, the man is the one expected to bring new things home, but if the woman tells you to go and get circumcised, I would want to know where she saw it."

On whether participants would advice a male relative or friend to go for male circumcision, one participant said; "I can only advice my male relatives or my friends to go for circumcision if they are young." Another participant stated that "if my relatives or friends are willing to undergo the procedure I can encourage them to do so."

When asked for possible reasons why the uptake of male circumcision was low in Gulathi area among adult males, the following responses were given : Participant A said "lack of knowledge about male circumcision has a negative effect on the uptake of circumcision," Participant H said "fear of pain prevents a number of men from accessing male circumcision." Participant F said "the issue of being asked to go through counselling and testing for HIV is causing people to shun the procedure." Generally most participants cited lack of knowledge and lack of sensitization as being responsible for the low uptake of male circumcision.

\section{The success of circumcision in HIV prevention Demographic characteristics}

VII. Interview guide with service providers

All the interviewees were from the district hospital and were comprised of three senior nurses in the district. The interviewees were mostly involved in the sentitization programme of male circumcision. However, it was noted that all of them were employees of the Ministry of Health who did not come from Matabeleland South Province. The locals view these employees as foreigners which were assumed to have negative implications to the recipients in terms of instilling confidence.

\section{The success of circumcision in HIV prevention}

When asked to comment on the success of the programme, all the three interviewees agreed that the programme was fairly successful. The other interviewee revealed that the majority who were circumcised were the young males especially the school boys who were less resistant and easily accessible.

When asked to comment on which age group had the highest turn, all the interviewees said "the school going children". One interviewee said the reason is that "school children are easy to group together and sensitize whilst the out of school youths and adults are resistant. The other interviewee said "most of adult males are working out of the country therefore, are not always available.'

When asked on the issue of counselling and testing for HIV before the procedure, they all said "that is the policy as of now." 
When asked to comment on the personnel involved in the male circumcision programme. The interviewees concurred that the health personnel came from the district hospital were also employed by a nongovernmental organization. When asked to comment on what they thought could be done to attract more men to the programme, one interviewee said "awareness campaign can be employed," the other said "if community leadership and other stakeholders are involved, the uptake of male circumcision could improve.'

\section{Discussion}

The researcher's findings revealed that all males had heard about male circumcision through different sources. The findings revealed that the most common source of information was the clinic, because from all the mentioned sources, the clinic was the highest at 33\%. The study also revealed that the majority of males $(87 \%)$ knew that male circumcision offers some advantages. It was also noted that some respondents knew that male circumcision was done to prevent some sexually transmitted infections and maintain some hygienic purposes.

The study also highlighted that the majority of males disagreed that circumcision practice was part of their culture and some males felt that they needed more information to understand the philosophy underlying the concept of male circumcision since it was a new phenomenon with contradictory interpretations. The majority of males (69\%) argued that by being compelled to first go through HIV screening process- that interfered with their democratic decisions as they felt that some were not ready to know their HIV status. It was also revealed that seventy-six percent of men preferred to be circumcised at the clinic because of the benefits of medication, this view is supported by WHO \& UNAIDS, 2009). The revelation that circumcision does not enhance sexual pleasure unless if it was done during childhood is also confirmed in the studies carried out by Dunsmuir \& Gordon, (1999). Although it was not scientifically proven, the majority revealed that male circumcision reduces sexual pleasure. It is in this area that more studies need to be carried out to come out with a scientific conclusion on the question whether male circumcision affects sexual libido if so, to what extent and with what effect?

This study discovered that lack of sensitization and lack of knowledge were responsible for lack of low uptake of male circumcision. Adding to the list was fear of pain during and after the procedure.

The study also unearthed that fifty-two percent of the uncircumcised young married males would not be circumcised because of the 6 weeks abstinence post-operation. It was also noted that the issue of being attended to by female health workers at circumcision surgical operation exercises was not a deterrent issue as the majority of the respondents $(88 \%)$, were not affected.

In this study, it was confirmed that sexual partners have no influence over men's decision to be circumcised. It was even highlighted that the community is a predominately patriarchic ally cultured and women are secluded from discussing or influencing their husbands to go for circumcision.

The study revealed that the majority who were circumcised were the school pupils between $15<21$ years. It was therefore, noted that, the majority would not comment on whether they abstained or not because the researcher concluded that they were not yet sexually active. It was also discovered that the out of school youths (school leavers as affectionately called) and the adults were not easy to group and give them information since the majority of the adult males were out of the country, for example, working in the neighbouring countries like South Africa, Botswana or Namibia.

\section{Conclusion}

- The research findings revealed that the attitudes of males were casued by different issues such as fear of risks associated with circumcision.

- The issue of a foreign practice to culture of people may cause males to shun the programme.

- The study discovered that if men are compelled to go through HIV screening process before undergoing circumcision, they are likely to shun the circumcision programme.

- The study unveiled that if circumcision was done at an early age, it would not affect one's sexual life.

- The present study also found that school children were easy to group and sensitize unlike in the case school leavers and adult males.

- This research project unveiled that adult males were not completely shunning circumcision programme, because most men were found to be working out of the country.

- Finally, the study revealed that information which was circulating among the target population was at times inadequate which impeded men's attitudes towards the programme.

\section{Recommendation for Matopo District}

$>$ There is a need to cover the knowledge gap at the clinics in order to make personnel at grassroot level be able to impart relevant information to the target population.

$>$ Availability of resources such as fliers and documents accessible to the public is crucial in the dissemination of correct information to demystify wrong perceptions and inaccurate ideas about the circumcision programme. 
$>$ Advocacy for a policy which allows men free access to circumcision procedure without being firstly expected to be HIV tested is assumed would influence more men to participate.

$>$ With adequate information and knowledge, the target population is likely to comprehend the need for them to abstain from sexual intercourse for the period of six weeks post operation.

$>$ Involvement of the community leadership and other stakeholders so that they can empower women to be in a position to influence their sexual partners to go for male circumcision without being blamed of infidelity

$>$ The personnel involved in the sensitization and surgical operations need to involve the local people who are familiar with the cultural beliefs, customs and language of the target population is of paramount importance in attracting the locals to undertake male circumcision.

\section{References}

[1]. Chihambakwe, W. \& Nkala, P. P. (2012) Project Planning and Management, Module BSCC 410. Harare, ZOU.

[2]. De Vaus, D.A. (2001) Research design in social research. SAGE Publication.

[3]. Dunsmuir, W.D. and Gordon, E.M. (1999). The history of circumcision, Department of Urology.

[4]. St. George's Hospital NHS Trust. Tooting. London UK. BJU International Vol. 83.

[5]. Durlak, J.A. and Dupre (2008) Implementation matters : A review of research on the influence of implementation on programme outcome and the factors affecting implementation. Loyola University Chicago Springer Science and Business Media.

[6]. Dr. Emeagwali, G. (2001). Female circumcision revisited. Africa update news letter.

[7]. Fraser, N. Ruark, A.H. Gorgens, M. James V. Milanzi, A. Colvin, M. Ibbertson, H. Mpofu, N.

[8]. Nxima (2011). Zimbabwe Analysis of HIV epidemic, Response and modes of transmission. National Aid Council.

[9]. Gayre, R. of Gayre (1972). The origion of the Zimbabwean civilization. Galaxie Press.

[10]. Gwata, F. (2009). Traditional male circumcision : What is its socio-cultural significance among Young Xhosa men? Centre for social science research - AIDS and society research unit. Working paper No. 264.

[11]. Hagazy, A.A. and Al-Rukban, M.O. (2012). Male circumcision : review and authors perspective. The health review Saudi Arabia.

[12]. Haider, H. (2009) Community-based approaches to peace building in conflict affected and fragile contexts. International Development University of Birmingham.

[13]. Hargreave, T. (2010). Male circumcision ; toward a WHO normative practice in resource limited settings. Asian of Andrology Review.

[14]. Israel, B.A. Krieger, J. Vlahov D, Ciske S, Foley M, Fortin P, Guzman J.R, Lichtenstein R, McGranaghan R, Patermo A and Tang G. (2006). Challenges and Facilitating factors in sustaining community based particiopatory research partnership : lesson learned from the Detroit, New York City and Seatle urban research centres. Journal of urban health : Bullettin of the New York academy of medicine Vol. 83 No. 6

[15]. Kahari L. (2013). A multimodal doscurse analysis of selected male circumcision posters used in Zimbabwe. Global journal of arts humanities and social sciences Vol. No. 4 European centre for research training and development UK.

[16]. Khumalo-Sakutukwa G, Lane T, Van-Rooyen H, Chingono A, Humphries H, Timbe A, Fritz K,

[17]. Chirowodza A. and Morin S.F. (2013). Culture, health and Sexuality : An international journal research, intervention and care. Department of Medicine, AIDS Research Centre, University of Califonia San Franscisco U.S.A.

[18]. Leedy P.D. and Ormrod J.E. (2001). Practice Research, Planning and Design. $7^{\text {th }}$ edition, upper Saddle River Merril Prentice Hall.

[19]. Macintyre K, Moses N, Andrino poulos K, Borstein M, Ochieng A, Muraguri N, Peacock E, Cherutich P, Hurley E.A. and Betrand J.T. (2013) Exploring aspects of demand creation and mobilization for male circumcision among older men in Turkana, Kenya. Research to prevention USAID Project search.

[20]. Male circumcision module (n.d) $1^{\text {st }}$ edition SAVE tookit SAVE the children.

[21]. Mandova E, Mutonhori T and Mudzanire S. (2012) An analysis of Hoko as indigenous knowledge systems. Internatuional journal of academic in progressive education and development Vol. 1 No. 4.

[22]. Mateveke P, Mashoko D. Mateveke A (2012). Perceptions of people towards male circumcision as a technical method to reduce HIV and AIDS infection in Masvingo district of Zimbabwe. Journal of AIDS and HIV Research Vol. 4 No.

[23]. Neville C. (2007). Introduction to research and research methods. Bradford University school of management effective learning service.

[24]. Nkosi M. (2013). The nature and causes of male circumcision. Clermount KwaDabeka in KwaZulu Natal South Africa. 